\title{
Parameter Optimization via the Taguchi Method to Improve the Mechanical Properties of Bamboo Particle Reinforced Polylactic Acid Composites
}

\author{
M. R. Nurul Fazita, ${ }^{*}$ Nurnadia Johary, H. P. S. Abdul Khalil, Najieha Norazli, \\ A. A. Azniwati, and M. K. Mohamad Haafiz
}

\begin{abstract}
Reinforcement with natural fibres is a common method to improve impact properties of poly(lactic acid) (PLA). In this study, composites made from PLA and bamboo particles were melt-compounded in a twin-screw extruder and formed by compression moulding. Tensile, flexural, and impact tests were conducted. Particle size (A), particle loading (B), screw speed (C), and die temperature (D) were varied at three levels. Tensile strength and modulus, flexural strength and modulus, and impact strength were the response variables. The experiment design was based on Taguchi's (L9) orthogonal array. Through variance analysis, the particle loading was found to be the dominant factor influencing the mechanical properties, followed by die temperature. The optimum parameters were validated with a confirmation test. The results showed a noticeable improvement of impact properties compared to neat PLA by $55 \%$, without compromising tensile and flexural properties. Flexural strength, flexural modulus, and tensile modulus of the composites were greater than that of pure PLA. However, only tensile strength was reduced by about $28 \%$ compared to pure PLA. Importantly, the DOE method with maximizing the desirability properties was found to be an effective systematic approach to identify an optimal parameter setting of the extrusion moulding process.
\end{abstract}

Keywords: Polylactic acid; Bamboo particles; Composites; Taguchi method; Mechanical Properties

Contact information: Division of Bioresource Technology, School of Industrial Technology,

Universiti Sains Malaysia, Penang 11800 Malaysia;

*Corresponding author: fazita@usm.my (M. R. Nurul Fazita)

\section{INTRODUCTION}

In the past years, biodegradable polymer has been an active subject of research and development with two main environmental concerns: the petroleum supplies are plummeting and there is an overload of plastic waste accumulation in landfills. If plastic production can stop depending on petroleum supplies that soon will decrease, nonrenewable resources can be preserved (Gamon et al. 2013). The excessive use of petroleum-based plastics will generate a huge amount of non-compostable solid wastes in landfills, which can cause serious depletion of landfill capacities (Ho et al. 2015). The concern of plastic disposal has increased as society has become aware of preserving the environment. Government environmental policies have been implemented to force industries to find environmentally friendly material (biodegradable material) to substitute the conventional non-biodegradable material to be used in applications such as automotive, packaging, and construction.

In development of green composites, natural fibres are mixed with biodegradable polymers including starch (Jumaidin et al. 2017), soybean plastics (Boontima et al. 2015),

Nurul Fazita et al. (2021). "Bamboo- PLA composites," BioResources 16(1), 1914-1939. 1914 
polyhydroxyalkanoate (PHA) (Chan et al. 2016), polyhydroxybutyrate (PHB) (TorresTello et al. 2017), polycaprolactone (PCL) (Sarasini et al. 2017), and polylactic acid (PLA) (Zhang et al. 2013; Siakeng et al. 2017). PLA has commercially attractive features such as its good optical, physical, mechanical and barrier properties, good appearance, low toxicity, and good processability. PLA is now one of the most promising among biodegradable polymer due to its remarkable mechanical properties as an alternative to conventional synthetic polymer (Bax and Müssig 2008; Ghaffar et al. 2018). PLA also can be recycled or disposed without harming the environment. PLA can be used for making plastic bags for household bio-waste, barriers for sanitary products and diapers, planting cups, and disposable cups and plates. The drawbacks of PLA include its relatively high cost in comparison to commodity plastics, its low impact strength, its low ability in resisting thermal deformation, and its brittle nature (Lu et al. 2014). To make it suitable for many technical applications, natural fibre is introduced into the PLA matrix as reinforcement. In this way the production cost of PLA composites can be reduced because less of the PLA will be used (Shibata et al. 2004).

Natural fibres have been considered as a potential reinforcement in biopolymer composites due to their excellent mechanical properties, biodegradability, renewable character, abundant availability, low cost, low density, accessibility, high specific modulus, and relatively high strength (Yu et al. 2014). Natural fibres as reinforcement to PLA matrix can be regarded as an ideal alternative to increase the mechanical performance of the composites as well as making it environmentally friendly. There are many natural fibres that have been studied to reinforce polymers, such as kenaf (Ochi 2008), hemp (Masirek et al. 2007), jute (Gupta et al. 2016), flax (Duhovic et al. 2009), and wheat straw (Ghaffar et al. 2017; Chougan et al. 2020). Among natural fibres available, it can be argued that bamboo fibres are the most suitable candidate as reinforcement for PLA matrix due to their favorable properties (Yu et al. 2014; Liu et al. 2018; Long et al. 2019; Chen et al. 2020; Wang et al. 2017; Zhang et al. 2020; Zuo et al. 2020). In this research, a specific type of bamboo species known as Gigantochloa scortechinii (Buluh Semantan) was chosen as reinforcement. Semantan bamboo is a significant commercial species that grows rapidly and is vastly available in forests throughout Malaysia (Rassiah et al. 2017).

Most studies on PLA-reinforced bamboo fibre composites have been primarily focused on improving their mechanical properties by modifying the natural fibre without optimizing the parameters, regardless of the process they were using (Lee and Wang 2006; Yu et al. 2013, 2014). Different studies have experimented with different composites formulations; different extrusion conditions were also reported in these studies (Ogbomo et al. 2009; Bourmaud and Baley 2010; Sawpan et al. 2011; Gamon et al. 2013). Bamboo fibre was shown to be the most effective reinforcement material among all studied reinforcements (Nuthong et al. 2013). The cited authors showed that the interfacial bonding between bamboo fibres and the PLA matrix were better than vetiver grass fibres and coconut fibres. Tokoro et al. (2008) also showed that the addition of bamboo fibres improves the impact strength, thermal properties, and heat resistance. PLA composites reinforced by bamboo fibres have remarkable mechanical properties. Iwatake et al. (2008) showed that the tensile modulus of PLA increased as the fibre loading amount was increased, but at the same time it led to various problems, such as losing properties, e.g., yield strain, which resulted in decreased strength. Therefore, the recent research initiative was to use the Taguchi approach to predict the parameters affecting the mechanical properties of the composite, as well as obtaining an optimum set of parameters to produce a composite with the "desired" mechanical properties. Navaneethakrishnan and 
Athijayamani (2015) demonstrated that the mechanical performance characteristics of a plant based natural fibre and particle reinforced polymer composite can be effectively improved via the Taguchi method. A study by Rawi et al. (2013) resulted in desirable tensile and flexural properties and acceptable impact performance for bamboo fabric-PLA composite sheets synthesized with parameters determined via the Taguchi method. Although there have been some recent studies that investigated the mechanical behaviours of natural fibre reinforced polymer composites, the application of experimental design for comparative analysis of the effects of the parameters on the mechanical properties of bamboo particle reinforced PLA composites is limited.

Considering the use of short bamboo fibres, a twin screw extrusion method was selected. Extrusion is the process of converting a raw material into a product of uniform shape and density by forcing it through a die under controlled conditions. Extrusion can be operated continuously, which allows consistent product flow at relatively high throughput rates (Bhairav et al. 2016). Rosato (2013) points out that extrusion is the most common method used to manufacture thermoplastic worldwide. Single screw and twin-screw extruders provide vastly different shearing and mixing conditions during the process. Twin screw extruders operate with a feeding and mixing zone and consists of screws that are available in multiple shapes. Salleh et al. (2014) stated that short fibres or fillers are easy to blend with a polymer matrix by using this system because the mixtures pass through a few mixing blocks. Treece and Oberhauser (2006) expressed that twin screw extruders are mostly preferred to achieve a good homogeneity of fibres in the composite.

As the demand from the bioplastic industry has increased, multiple studies have been carried out on single-screw and twin-screw extruders with their own screw profiles and temperature profiles. Hence, there were a wide range of experimental conditions to be optimized for the same natural fibres and polymers. Polylactic acid is one of the most published bio-based polymers that is associated with natural fibres. Several process conditions for PLA composites reinforced with natural fibres are shown in Table 1.

Material selection and processing parameters play a critical role in determining the performance of the composites (Gamon et al. 2013; Zhang et al. 2013; Gallos et al. 2017). However, not much work has been done on the selection of parameters during the extrusion process to improve the mechanical properties of PLA-reinforced bamboo particle composites, especially their impact properties. Although there are many research articles has been published on the natural fibres reinforced PLA composites, unfortunately most of the available research works have focused only on the production and characterization of natural fibres reinforced PLA composites. Thus, the current study put an emphasized on how the material selection and processing parameters can be designed with the help of Design of Experiment (DoE) via the Taguchi method to improve different mechanical properties of the composites. This research signifies that material and processing parameters can be manipulated to improve the quality of the PLA reinforced bamboo particle. The primary objective of this study was to optimize the material and processing parameters during the production of PLA reinforced bamboo particle composites to improve the mechanical properties of these composites. The Taguchi method was used to determine significant parameters. Four primary parameters were considered: bamboo particle loading and bamboo particle size, as well as the screw speed, and die temperature of the twin screw extruder. The tensile, flexural, and impact properties were the responses. The physical, thermal, and morphological properties of the composites were also studied.

Nurul Fazita et al. (2021). "Bamboo- PLA composites," BioResources 16(1), 1914-1939. 1916 
Table 1. Process Conditions of Single*/Twin ${ }^{* *}$ Screw Extruder for PLA Reinforced with Natural Fibres

\begin{tabular}{|c|c|c|c|c|c|c|c|c|c|c|}
\hline $\begin{array}{l}\text { Natural } \\
\text { Fibres }\end{array}$ & $\begin{array}{l}\text { Fibre } \\
\text { Size } \\
(\mu \mathrm{m})\end{array}$ & $\begin{array}{l}\text { Fibre } \\
\text { Load } \\
\text { (wt\%) }\end{array}$ & $\begin{array}{l}\text { Screw } \\
\text { Speed } \\
(\mathrm{rpm})\end{array}$ & $\begin{array}{c}\text { Temperature } \\
\text { Profile } \\
\left({ }^{\circ} \mathrm{C}\right)\end{array}$ & $\begin{array}{l}\text { Tensile } \\
\text { Strength } \\
\text { (MPa) }\end{array}$ & $\begin{array}{c}\text { Tensile } \\
\text { Modulus } \\
\text { (GPa) }\end{array}$ & $\begin{array}{c}\text { Flexural } \\
\text { Strength } \\
\text { (MPa) }\end{array}$ & $\begin{array}{c}\text { Flexural } \\
\text { Modulus } \\
\text { (GPa) }\end{array}$ & $\begin{array}{c}\text { Impact } \\
\text { Strength } \\
\left(\mathrm{kJ} / \mathrm{m}^{2}\right)\end{array}$ & References \\
\hline Hemp & 4900 & 10 to 30 & $100^{* *}$ & 175 to 190 & 50 to 76 & 3.5 to 8.2 & - & - & 1.0 to 2.7 & $\begin{array}{c}\text { Sawpan et al } \\
(2011)\end{array}$ \\
\hline Abaca & - & - & $100^{* *}$ & 200 & 74 & 3.3 to 8.0 & - & - & 6.0 & $\begin{array}{c}\text { Bledzki et al. } \\
(2010)\end{array}$ \\
\hline Jute & - & - & $100^{* *}$ & 200 & 81.90 & 3.4 to 9.6 & - & - & 5.0 & $\begin{array}{l}\text { Bledzki et al. } \\
(2010)\end{array}$ \\
\hline Miscanthus & 230 & 10 to 40 & $\begin{array}{l}100 \text { to } \\
300^{* *}\end{array}$ & 165 to 190 & 50 to 54 & 6.0 to 6.4 & 70.0 & 4.0 & - & $\begin{array}{c}\text { Gamon et al. } \\
(2013)\end{array}$ \\
\hline Miscanthus & - & 20 to 40 & $63^{*}$ & 175 to 200 & 50.9 to 59.1 & 2.4 to 3.2 & - & - & - & $\begin{array}{l}\text { Ragoubi et } \\
\text { al. (2012) }\end{array}$ \\
\hline Flax & 1 & 25.7 & $20^{*}$ & 190 & 55.4 & 3.8 to 7.4 & - & - & 9.1 & $\begin{array}{l}\text { Bourmaud et } \\
\text { al. (2015) }\end{array}$ \\
\hline Flax & 4 & 30 & $20^{*}$ & 175 to 185 & - & - & - & - & - & $\begin{array}{l}\text { Bourmaud et } \\
\text { al. (2010) }\end{array}$ \\
\hline Kenaf & 3 & 10 to 30 & $80^{*}$ & 200 & 35.5 to 39.2 & 1.40 to 1.90 & - & - & - & $\begin{array}{l}\text { Pan et al. } \\
\text { (2007) }\end{array}$ \\
\hline \multirow{4}{*}{ Bamboo } & 260 & \multirow{4}{*}{$\begin{array}{c}20 \text { and } \\
40\end{array}$} & \multirow{4}{*}{$\begin{array}{c}100,150, \\
225, \text { and } \\
300^{\star *}\end{array}$} & \multirow{4}{*}{165} & $50-55$ & $6.75-9.00$ & 69-78 & $4.1-6.0$ & - & \multirow{4}{*}{$\begin{array}{c}\text { Gamon et al. } \\
(2013)\end{array}$} \\
\hline & 200 & & & & $55-56$ & $7.00-10.50$ & 72.83 & $4.8-7.0$ & - & \\
\hline & 160 & & & & $49-52$ & $6.00-9.00$ & $66-69$ & $4.0-5.7$ & - & \\
\hline & 80 & & & & $46-49$ & $5.50-8.00$ & $60-63$ & $3.7-5.2$ & - & \\
\hline
\end{tabular}




\section{EXPERIMENTAL}

\section{Materials}

Semantan bamboo (Gigantochloa scortechinii) was purchased from local sources (Bamboo Village, Kuala Lumpur, Malaysia). The bamboo provided was air-dried and cut into small pieces. Subsequently, the bamboo pieces were ground into particle size by using a Riken grinder (model RAB- 15T11S3, Wakō, Japan). The bamboo particles (BP) were sieved with a Retsch Test Sieve Model 5667 (Haan, Germany) into three ranges: 50 to 150 $\mu \mathrm{m}, 150$ to $250 \mu \mathrm{m}$, and 250 to $425 \mu \mathrm{m}$.

Image $\mathbf{J}$ software was used with the scanning electron microscope images of the fibres to determine the average dimensions. Polylactic acid (PLA) (Ingeo biopolymer 2003D), manufactured by Nature Works LLC (Minnetonka, MN), was purchased from Innovative Pultrusion (Negeri Sembilan, Malaysia). The polymer was supplied in the form of pellets and the physical and mechanical information of the PLA pellets are shown in Table 2.

Table 2. Mechanical and Physical Properties of PLA Based on Datasheet

\begin{tabular}{|c|c|c|}
\hline Physical Properties & PLA & ASTM Method \\
\hline Specific gravity & 1.24 & D792 \\
\hline MFR $\left(\mathrm{g} / 10\right.$ in $\left(210^{\circ} \mathrm{C}\right.$ and $\left.\left.216 \mathrm{~kg}\right)\right)$ & 6 & D1238 \\
\hline Clarity & \multicolumn{2}{|c|}{ Transparent } \\
\hline Mechanical Properties & 60 & D882 \\
\hline Tensile strength $(\mathrm{MPa})$ & 3.5 & D882 \\
\hline Tensile modulus $(\mathrm{GPa})$ & 16 & D256 \\
\hline Notched Izod impact $(\mathrm{J} / \mathrm{m})$ & 55 & E2092 \\
\hline Heat distortion temperature $\left({ }^{\circ} \mathrm{C}\right)$ &
\end{tabular}

\section{Methods}

Preparation of the composites

The bamboo particles were dried in an oven at $105{ }^{\circ} \mathrm{C}$ for $24 \mathrm{~h}$ prior to processing in order to minimize moisture content and to avoid porous structures, which may result in low product strength (Klyosov 2007). The PLA was also dried in a vacuum oven at $70{ }^{\circ} \mathrm{C}$ for $24 \mathrm{~h}$ before it could be used. The PLA-BP biocomposites were prepared at different conditions using a Lab Tech $26 \mathrm{~mm}$ co-rotating twin screw extruder according to the conditions listed in Table 2.

Figure 1a illustrates the extrusion process of the BP and the PLA. After extrusion, the extrudate materials were dried at room temperature for $24 \mathrm{~h}$ before pelletizing. The pelletized biocomposites were vacuum dried at $70{ }^{\circ} \mathrm{C}$ prior to hot compression moulding. The pelletized biocomposites were compressed at $190{ }^{\circ} \mathrm{C}$ in a metal flat frame mould (200 $\mathrm{mm} \times 200 \mathrm{~mm} \times 3 \mathrm{~mm}$ ).

The biocomposites were preheated at $190{ }^{\circ} \mathrm{C}$ for $10 \mathrm{~min}$, compressed at $190{ }^{\circ} \mathrm{C}$ for $5 \mathrm{~min}$ at $3.44 \mathrm{MPa}$ and cool pressed at room temperature. Figure $1 \mathrm{~b}$ shows the PLA-BF biocomposite sheet after being compression moulded. 


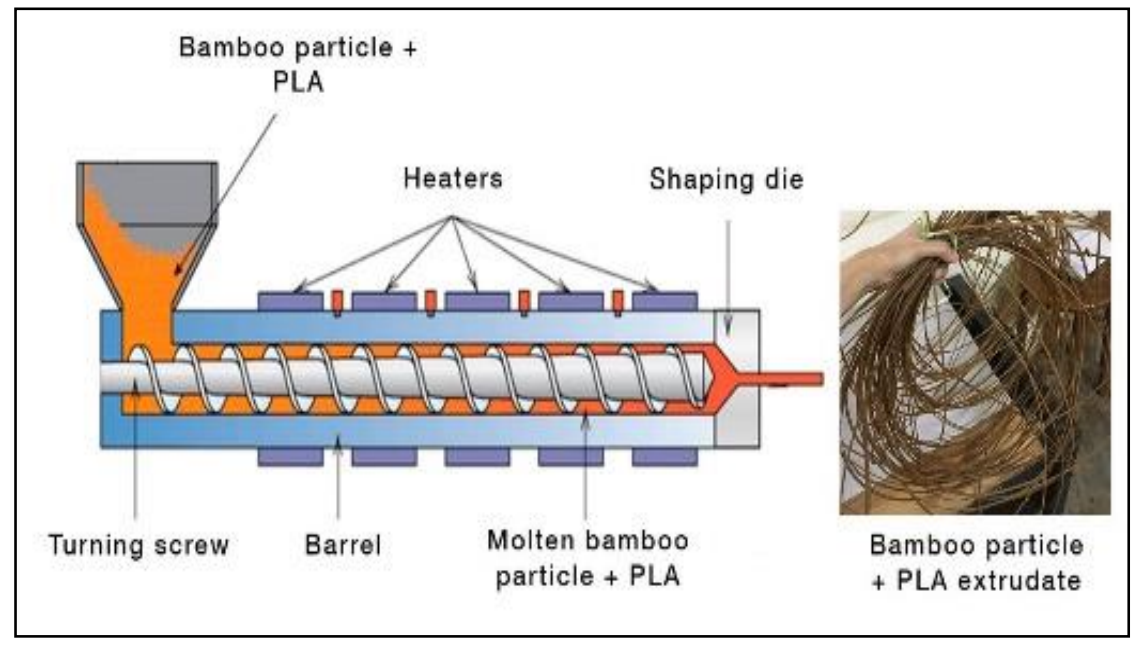

(a)

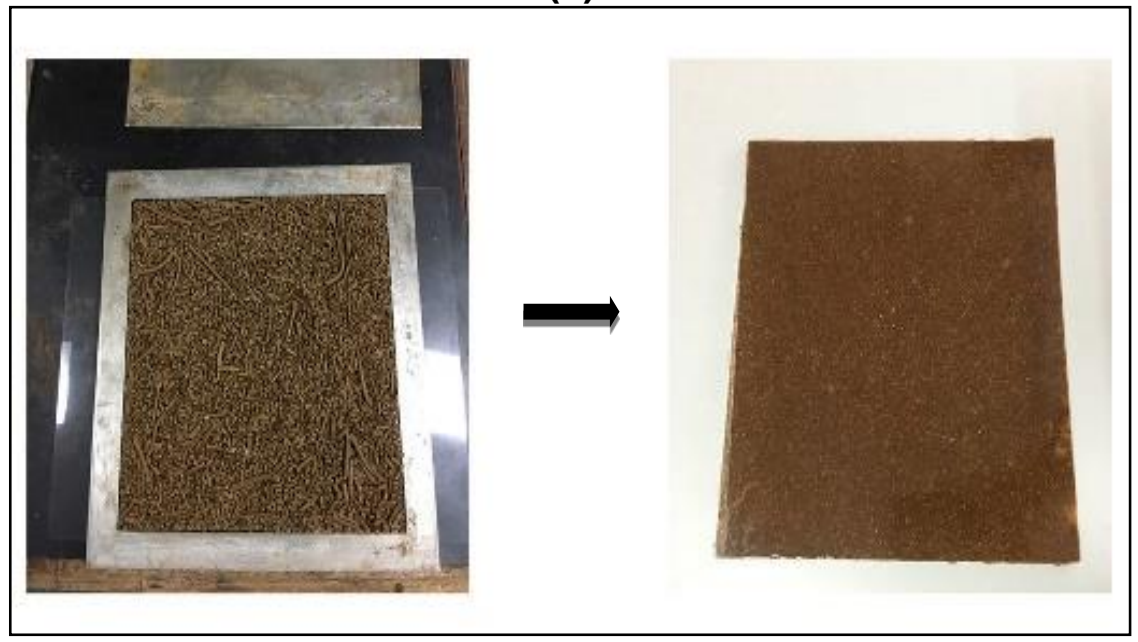

(b)

Fig. 1. (a) Compounding of the PLA and bamboo particle using twin screw extruder; (b) the PLA$\mathrm{BP}$ biocomposite sheet after being compression moulded

\section{Mechanical Tests of Biocomposites}

The mechanical behaviour of the PLA biocomposite sheets were investigated by conducting three different mechanical testing processes: tensile, flexural, and Izod impact. At least five identical test specimens were prepared for each mechanical test. The averages were taken, and the corresponding standard deviations were calculated.

\section{Tensile test}

The PLA biocomposites test specimens were tested according to ASTM standard D638-10 (2010) to measure their tensile properties. The samples were cut according to the specification for Type I specimens. A universal testing machine (model 5969-50kN Electro-Mechanical UTM) was used to test the samples with a gauge length of $50 \mathrm{~mm}$ and a crosshead speed of $5 \mathrm{~mm} / \mathrm{min}$. 


\section{Flexural test}

Three-point bending tests were conducted in accordance with ASTM standard D790-10 (2010) to measure the flexural properties using an universal mechanical testing machine (model 5969-50kN Electro-Mechanical UTM). Seven samples were cut according to the standard specification and the samples were loaded in a three-point flexural with the recommendation span to depth ratio of 16 to 1 . The testing was performed at a crosshead speed according to the standard.

\section{Impact test}

An Izod impact test was conducted according to ASTM standard D256-10 (2010) using a GOTECH impact tester (model GT-7045-MDL, Baton Rouge, LA) to investigate the toughness of the PLA-BP biocomposites. Beforehand, the samples were cut into rectangular biocomposite strips (64 $\mathrm{mm} \times 12.7 \mathrm{~mm} \times 3 \mathrm{~mm}$ ). A $45^{\circ} \mathrm{V}$-shaped notch was made at the centre part of the sample with the GOTECH notching machine (model GT7016-A2). The depth under the notch was $10.2 \mathrm{~mm}$.

\section{Scanning Electron Microscopy (SEM)}

A FEI Quanta FEG 650 SEM was used to study the morphological characterization of the biocomposite fractured surface and size determination of the bamboo particles. The biocomposite samples were thoroughly cleaned, air-dried, and then mounted on an aluminium SEM sample holder with double sided tape. The samples were then coated with gold and left to dry at room temperature for $2 \mathrm{~h}$ before SEM could be performed. The SEM analyses were performed at $5 \mathrm{kV}$ and at 100x magnifications, while Image J software was used to determine the average BP size. As shown in Fig. 2, the SEM images with particle size low, medium, and high are labelled (a), (b), and (c), respectively.

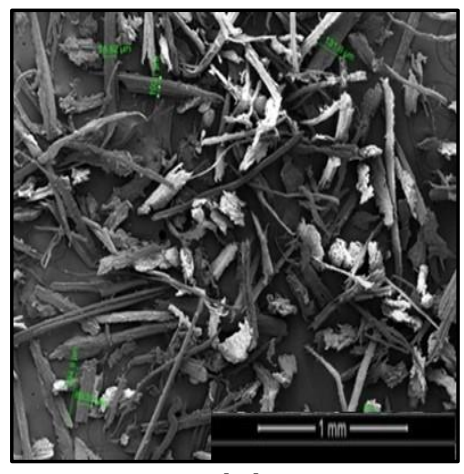

(a)

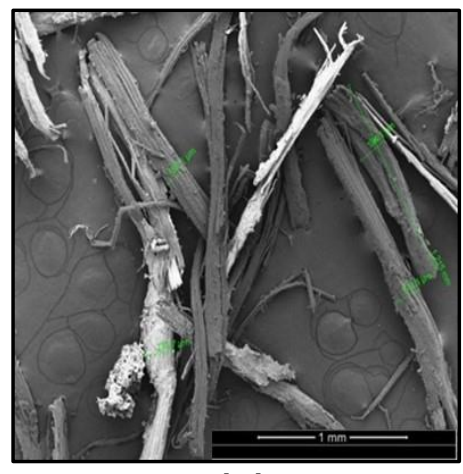

(b)

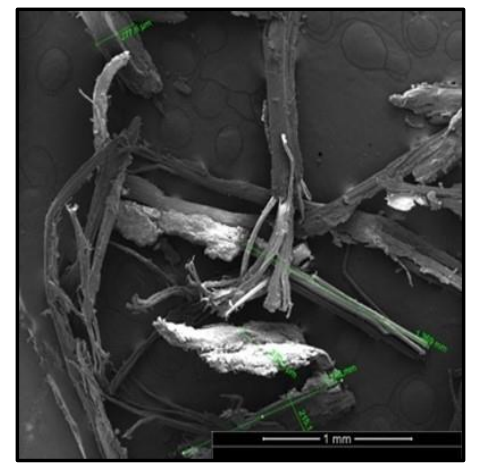

(c)

Fig. 2. SEM images of the bamboo particles with (a) low, (b) medium, and (c) high particle sizes

\section{Design of Experiments (DoE): Taguchi Method}

The design of experiments (DOE) is a highly effective tool to analyse the influence of process parameters in terms of performance. Typically, a simple approach in the research process is used, in which numerous experimental runs are required to explore the relationship by changing one parameter at a time. Thus, the experimental design approach, e.g., the Taguchi method, can be introduced as an effective technique to reduce the number of experiments while retaining the quality of the data collection. 
The Taguchi method was used to optimize the design parameters because this systematic approach can be significantly minimizing the overall testing time and experimental cost. The proper selection of factors and their levels is the most important step at the early stage of the design of experiments process. Taguchi's method tests a pair of factors and provides the optimum results, thereby reducing the number of experiments, cost, and time (Joseph and Panneerselvam 2020).

The particle size (A), particle loading (B), screw speed (C), and die temperature (D) were selected as parameters. These parameters are varied at three levels. To study the complete effect of parameters, four factors at three levels require $3^{4}=81$ runs as per fullfactorial experiment, whereas Taguchi's approach reduced the number of experiments to 9. The minimum number of experiments that are required to conduct the Taguchi method can be calculated based on the degree of freedom approach. Taguchi's designs are usually highly fractionated, which makes them very attractive to practitioners. A quarter-fraction design, denoted as $2^{\mathrm{k}-2}$, consists of a fourth of the runs of the full factorial design. In this study, the orthogonal array chosen was the L9 $\left(3^{4-2}\right)$, which has 9 rows corresponding to the number of tests with four columns at three levels. The parameter settings at different level are given in Table 3. Minitab software (Version 16, Minitab Inc., State College, PA) was used to analyze the data statistically for each test conducted in this work.

Table 3. Experimental Layout Using A L9 Orthogonal Array and Output Performance

\begin{tabular}{|c|c|c|c|c|c|c|c|c|c|}
\hline $\begin{array}{c}\text { Exp. } \\
\text { No }\end{array}$ & $\begin{array}{c}\text { Particle } \\
\text { Size }(\mu \mathrm{m}) \\
(\mathrm{A})\end{array}$ & $\begin{array}{c}\text { Particle } \\
\text { Load } \\
\text { (wt\%) } \\
\text { (B) }\end{array}$ & $\begin{array}{c}\text { Screw } \\
\text { Speed } \\
(\mathrm{rpm}) \\
(\mathrm{C})\end{array}$ & $\begin{array}{c}\text { Die } \\
\text { Temp. } \\
\left({ }^{\circ} \mathrm{C}\right) \\
(\mathrm{D})\end{array}$ & $\begin{array}{c}\text { TS } \\
(\mathrm{MPa})\end{array}$ & $\begin{array}{c}\mathrm{TM} \\
(\mathrm{GPa})\end{array}$ & $\begin{array}{c}\mathrm{FS} \\
(\mathrm{MPa})\end{array}$ & $\begin{array}{c}\mathrm{FM} \\
(\mathrm{GPa})\end{array}$ & $\begin{array}{c}\text { IS } \\
(\mathrm{J} / \mathrm{m})\end{array}$ \\
\hline PLA & - & $x_{2}$ & 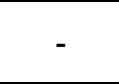 & - & $\begin{array}{l}57.60 \\
(0.89)\end{array}$ & $\begin{array}{c}4.87 \\
(0.20)\end{array}$ & $\begin{array}{l}88.47 \\
(1.78)\end{array}$ & $\begin{array}{c}3.42 \\
(0.35)\end{array}$ & $\begin{array}{l}19.84 \\
(0.86) \\
\end{array}$ \\
\hline R1 & 50 to 150 & 10 & 100 & 170 & $\begin{array}{l}40.62 \\
(2.83)\end{array}$ & $\begin{array}{c}5.56 \\
(0.14)\end{array}$ & $\begin{array}{l}62.05 \\
(1.15)\end{array}$ & $\begin{array}{c}3.85 \\
(0.35)\end{array}$ & $\begin{array}{l}31.57 \\
(3.19\end{array}$ \\
\hline $\mathrm{R} 2$ & 50 to 150 & 30 & 200 & 180 & $\begin{array}{l}52.13 \\
(2.75)\end{array}$ & $\begin{array}{c}7.30 \\
(0.33)\end{array}$ & $\begin{array}{l}69.23 \\
(2.31)\end{array}$ & $\begin{array}{c}4.65 \\
(0.07)\end{array}$ & $\begin{array}{l}23.61 \\
(2.39)\end{array}$ \\
\hline R3 & 50 to 150 & 50 & 300 & 190 & $\begin{array}{l}23.98 \\
(1.16)\end{array}$ & $\begin{array}{c}8.29 \\
(0.15)\end{array}$ & $\begin{array}{l}42.80 \\
(2.23)\end{array}$ & $\begin{array}{c}6.50 \\
(0.23)\end{array}$ & $\begin{array}{l}17.00 \\
(1.42)\end{array}$ \\
\hline $\mathrm{R} 4$ & 150 to 250 & 10 & 200 & 190 & $\begin{array}{l}40.10 \\
(0.29)\end{array}$ & $\begin{array}{c}5.70 \\
(0.21)\end{array}$ & $\begin{array}{l}80.10 \\
(1.59)\end{array}$ & $\begin{array}{c}3.56 \\
(0.77)\end{array}$ & $\begin{array}{l}29.82 \\
(1.43)\end{array}$ \\
\hline $\mathrm{R} 5$ & 150 to 250 & 30 & 300 & 170 & $\begin{array}{l}32.00 \\
(0.24)\end{array}$ & $\begin{array}{c}7.17 \\
(0.17)\end{array}$ & $\begin{array}{l}61.17 \\
(2.69)\end{array}$ & $\begin{array}{c}4.93 \\
(0.44)\end{array}$ & $\begin{array}{l}32.29 \\
(4.35)\end{array}$ \\
\hline $\mathrm{R} 6$ & 150 to 250 & 50 & 100 & 180 & $\begin{array}{l}44.65 \\
(0.91)\end{array}$ & $\begin{array}{c}5.02 \\
(0.32)\end{array}$ & $\begin{array}{l}14.80 \\
(2.20)\end{array}$ & $\begin{array}{c}5.17 \\
(0.49)\end{array}$ & $\begin{array}{l}22.39 \\
(2.10) \\
\end{array}$ \\
\hline $\mathrm{R} 7$ & 250 to 425 & 10 & 300 & 180 & $\begin{array}{l}44.73 \\
(1.77)\end{array}$ & $\begin{array}{c}3.92 \\
(0.73)\end{array}$ & $\begin{array}{l}91.90 \\
(1.31)\end{array}$ & $\begin{array}{c}4.36 \\
(0.16)\end{array}$ & $\begin{array}{r}35.62 \\
(3.68) \\
\end{array}$ \\
\hline $\mathrm{R} 8$ & 250 to 425 & 30 & 100 & 190 & $\begin{array}{l}27.43 \\
(2.08)\end{array}$ & $\begin{array}{c}7.00 \\
(0.37)\end{array}$ & $\begin{array}{l}64.75 \\
(0.50)\end{array}$ & $\begin{array}{c}5.18 \\
(1.09)\end{array}$ & $\begin{array}{l}24.31 \\
(2.25)\end{array}$ \\
\hline $\mathrm{R} 9$ & 250 to 425 & 50 & 200 & 170 & $\begin{array}{l}19.95 \\
(1.34)\end{array}$ & $\begin{array}{c}7.71 \\
(0.17)\end{array}$ & $\begin{array}{l}22.60 \\
(1.07)\end{array}$ & $\begin{array}{c}5.59 \\
(0.31)\end{array}$ & $\begin{array}{r}13.05 \\
(0.95) \\
\end{array}$ \\
\hline
\end{tabular}

Nurul Fazita et al. (2021). "Bamboo- PLA composites," BioResources 16(1), 1914-1939. 1921 


\section{Parameters selection}

Particle size (A)

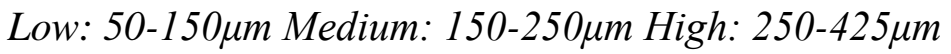

Pre-experimental findings showed that the highest range of fibre size that was chosen was 250 to $425 \mu \mathrm{m}$ due to the limitation of the particle size allowed for extrusion. A fibre size greater than $425 \mu \mathrm{m}$ will clog the die of the twin screw extruder. According to literature shown in Table 1, most fibre lengths were comprised between 0.5 and $55 \mathrm{~mm}$, but fibres shorter than $10 \mathrm{~mm}$ length were preferred. A 150 to $250 \mu \mathrm{m}$ fibre size was chosen as the intermediate value.

\section{Particle load (B)}

Low: 10 wt\% Medium: 30 wt\% High: 50 wt\%

According to literature, the mechanical performance of bamboo fibre composite increased as the bamboo fibre composition was increased, up to $60 \mathrm{wt} \%$, and it declined sharply as the fibre increased further (Yang et al. 2015). However, the twin screw extruder was not able to perform as well at $60 \mathrm{wt} \%$. A $50 \mathrm{wt} \%$ was chosen as the high limit for this study while $30 \mathrm{wt} \%$ was chosen as the intermediate value.

Screw speed $(C)$

Low: 100 rpm Medium: 200 rpm High: 300 rpm

The lowest screw speed chosen was $100 \mathrm{rpm}$. This speed was chosen according to the literature reported in Table 1, as most of the reported work in preparation of natural fibres reinforced PLA composites used a screw speed of $100 \mathrm{rpm}$. In addition, the highest speed for the twin screw extruder was up to $300 \mathrm{rpm}$. Too high of a screw speed can result in insufficient time for the mixing of particles and PLA to occur in the extruder. A screw speed of $200 \mathrm{rpm}$ was chosen as the intermediate value.

Die temperature $(D)$

Low: $170{ }^{\circ} \mathrm{C}$; Medium: $180^{\circ} \mathrm{C}$; High: $190{ }^{\circ} \mathrm{C}$

Natural fibres are sensitive to thermal degradation. However, too low a temperature will result in a high viscosity, causing the mixing of the fibres with the matrix to be harder to occur. Passing through the die was also an important step during the extrusion process. The die temperature must be kept constant because it is linked with compound viscosity. The die temperature can change the rheology behaviour of the PLA and bamboo particle compounded pellet (Gamon et al. 2013). Mechanical properties vary with temperature because of the difference in viscosities of the composite mixtures (Sallih et al. 2014). The upper limit of $190{ }^{\circ} \mathrm{C}$ was set due to concerns that at a higher temperature than $190{ }^{\circ} \mathrm{C}$, the bamboo particles might begin to thermally degrade. The lower die temperature limit was chosen to be $170{ }^{\circ} \mathrm{C}$, although the melting temperature of PLA was found to be approximately $152{ }^{\circ} \mathrm{C}$. This was due to the consequent formation of sharkskin on the composite sheets if a die temperature lower than $170^{\circ} \mathrm{C}$ was used.

\section{Analysis of Variance (ANOVA)}

To understand the significance of the impact of the parameters on the mechanical behaviour of the biocomposites, a one-way analysis of variance (ANOVA) was applied. The analysis was done performed using Microsoft Excel. 


\section{RESULTS AND DISCUSSION}

\section{Mechanical Properties of Composites}

The experimental results of the mechanical properties obtained from the L9 orthogonal arrays are shown in Table 3. The results showed that the addition of bamboo particles to the PLA composites enhanced all mechanical properties, except for tensile strength, in comparison to neat PLA. This could be due to poor bonding between the bamboo particles and the PLA, thus leading to poor tensile strength of the PLA-bamboo particle composites. This has been attributed to weak interfacial interaction between the hydrophobic PLA matrix and the hydrophilic bamboo fibres. An article published by Zhou et al. (2016) also reported that the reinforcement of PLA with natural fibres reduced the tensile strength as well as the lack of fibre dispersion due to a high degree of fibre agglomeration.

The SEM images of the PLA composites with different particle loads are shown in Fig. 3. In terms of poor tensile strength, Fig. 3c showed considerable fibre agglomeration, which occurred due to poor fibre dispersion, as well as several fibre pull outs, which occurred because of poor bonding. As mentioned by Mulinari et al. (2009), the mechanical behaviour of the composite is strongly dependent on the microstructural distribution of the reinforced particles in the matrix. Particle agglomerates act as defects or stress concentration sites for crack nucleation. The number of agglomerates increase as the particle loading percentage increases. The PLA composites with $10 \mathrm{wt} \%$ and $30 \mathrm{wt} \%$ particle load (as shown in Fig. 3a and Fig. 3b), had relatively better fibre dispersion; however, some fibre pull outs and fibre-matrix debonding were still observed.

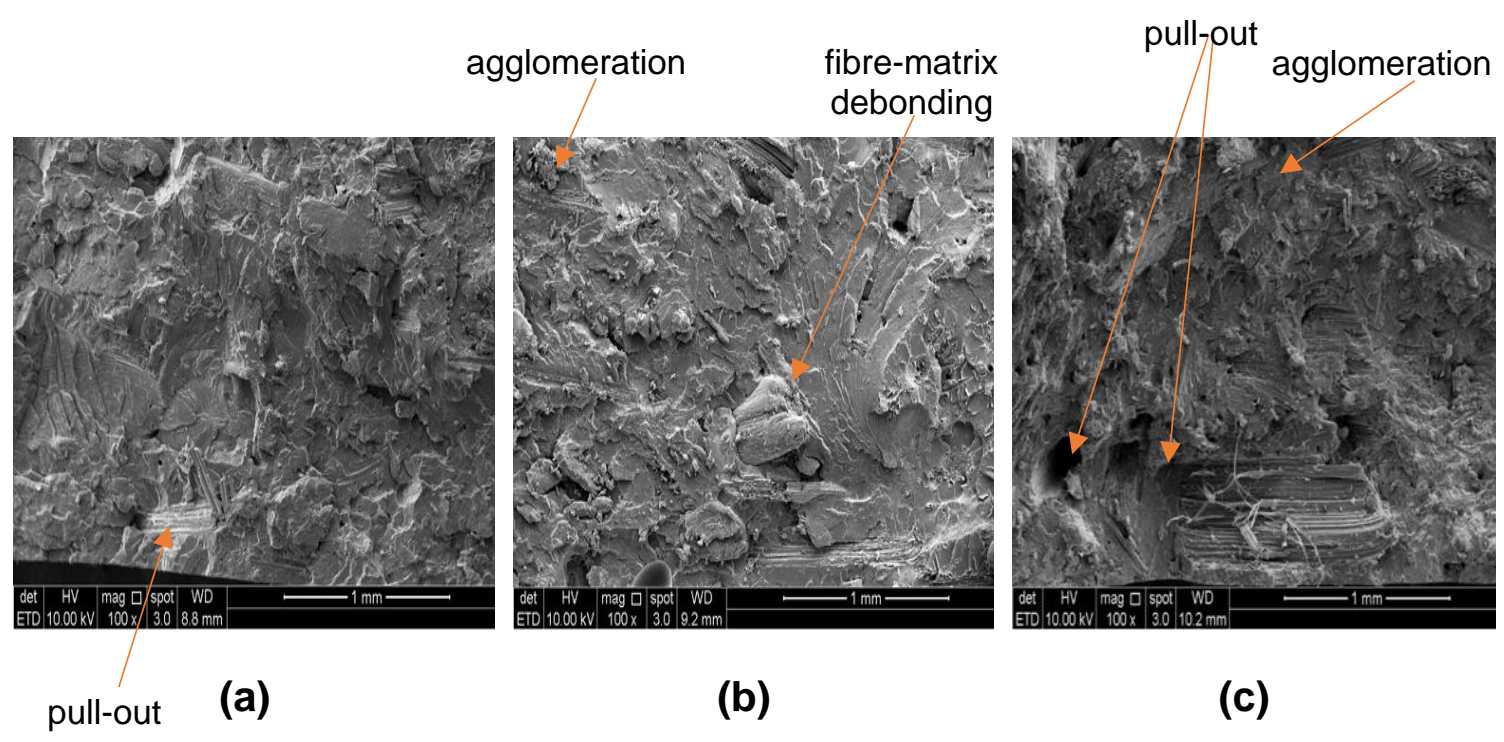

Fig. 3. SEM images of tensile fractured sample surfaces for (a) $10 \mathrm{wt} \%$ (b) $30 \mathrm{wt} \%$ (c) $50 \mathrm{wt} \%$ of PLA/BP composites

It was expected that a higher fibre content would result in better tensile properties in the PLA composites because the fibres have a higher tensile strength than the matrices. However, the results shown in Table 3 indicate that the tensile strength and flexural strength decreased with an increasing particle load. The agglomeration of bamboo fibres

Nurul Fazita et al. (2021). "Bamboo- PLA composites," BioResources 16(1), 1914-1939. 1923 
at a higher bamboo content might be the reason the tensile strength of the composites was reduced with the addition of more bamboo fibers. There are findings from literature that claimed at a certain point, the matrices cannot completely bind all the fibres (Shah et al. 2016). Thus, this results in failure occurring at the weak area. In the tensile test reported by Ismail et al. (2002), it was shown that the tensile strength of bamboo fibre reinforced natural rubber decreased as the fibre load increased. They reported that the composites tensile strength was due to the inability of the irregular shaped bamboo fibres to transfer the stresses to the polymer matrix. However, the flexural strength was higher than the tensile strength, because, for two samples of the same size, only one half of the sample was stressed from bending, while the whole sample was under tension, and fewer defects are involved in bending. This is because according, to Leguillon et al. (2015), amongst the two strength parameters, the tensile strength seems to be the only one to be a material parameter. The tensile and flexural modulus of PLA/BP composites exhibited remarkable improvement, by $70 \%$ and $90 \%$ respectively, in comparison to neat PLA. The tensile modulus of the PLA/BP composites increased as the particle load increased. This may be attributed to the increase in bamboo content, which has a higher stiffness than the matrix (El-Shekeil et al. 2014).

The results of the Izod impact tests are shown in Table 3, and it is apparent that the impact strength of all PLA/bamboo particles composites improved in comparison to neat PLA, except for R9. The improvement of the impact strength compared to neat PLA is owed to the presence of particles in the polymer matrix. Consequently, more energy can be absorbed during debonding. However, the decrease in impact strength for R9 was because at $50 \mathrm{wt} \%$, there were many fibres that were not completely surrounded by the polymer matrix and were in contact with other fibres. This will lead to less energy being absorbed during an impact. It may also be due to the induced micro-spaces between the fibre and the polymer. Hence, micro-cracks will occur upon impact, which can easily lead to crack propagation and decrease the impact strength of the composite (Yang et al. 2004; Zhao et al. 2008). The effect of each parameter on the mechanical properties of the PLA/BP composites will be discussed in detail in the Taguchi analysis section.

\section{Taguchi Analysis}

The orthogonal array of Taguchi experimental design was employed to determine the parameters at different levels in separated responses using the average of the experimental outputs. A Taguchi orthogonal array L9 $\left(3^{4-2}\right)$ with three logical levels for each parameter was used. The parameters mentioned in Table 3 were responsible for affecting the tensile, flexural, and impact properties. Analyses of the effects of the consolidation parameters were conducted on the average values of the tensile, flexural, and impact properties outputs using response graphs. An optimal set of conditions can be obtained by the calculated average values shown in the response graphs to achieve the greatest performance of the PLA/BP composites. Levels 1, 2, and 3 denote a low, medium, and high-level parameter setting, respectively. Note that a longer vertical line represents a higher influence of the parameter on the mechanical performance of the composite sheets. The horizontal line shows the average value of the composite performance. The highest values of each parameter were considered as the optimum set of process conditions.

\section{Tensile strength}

Figure 4 illustrates the response from the Taguchi analysis of tensile strength. The results in Fig. 4a show that the fibre load and die temperature had a large influence on the 
variability in composite tensile strength. Higher bamboo content leads to lower tensile strength. This poor performance is likely due to a lower amount of PLA present to transfer the fibres in the extruder, thus resulting in poor mixing of the bamboo particles and the PLA matrix. Lower amounts of PLA also restricted the ability of PLA to bind the fibres together in the composite sheets. Besides, high fibre loading also will lead to agglomeration in the composites, thus reduced the tensile strength of the composites. The agglomeration of bamboo particles is an indication of poor bonding or low interfacial adhesion strength between the filler and PLA matrix as also found in Wahyuni and Soeswanto (2019). The agglomerates provide defects that can develop quickly and trigger brittle fracture. For tensile strength, the interfacial action is favoured for the stress transfer from the matrix to the bamboo particles, so the tensile strength can be enhanced (Zhang et al. 2011).

For the die temperature, a low and high die temperature led to poor tensile strength. This could be due to the fact that at low die temperatures, the viscosity of the mixture of PLA and bamboo fibres in the extruder is relatively high. This leads to poor compounding between the PLA matrix and bamboo particles. In contrast, at a high die temperature, the viscosity might be too low. This will cause most of the bamboo fibres to easily transfer through the die. Therefore, more PLA will be left behind in the extruder without binding to bamboo fibres. It can be concluded that the best combination for obtaining optimal tensile strength in the composite sheets consists of a low-level particle load and a medium level die temperature, while the remaining parameters can be set to any level. It is clearly shown from the Taguchi analysis that the composite strength increases as the particle size decreases. This might be due to smaller particles having a higher total surface area that helps to transfer the stress more efficiently in the composite system, thus improving the tensile strength of the composites. Similar findings have also been reported by Fu et al. (2008) and Zakaria et al. (2018). The result reveals that the strength of the composite increases with decrease in the particle size. Zakaria et al. (2018) stated that the smaller size of fiber will increase interfacial interaction between fiber and matrix. Higher work hardening rate was also observed with decreasing the particle size. This is attributed to the formation of dislocation tangles around the particles, due to plastic incompatibility between the reinforcement and matrix, and the formation of a dislocation cell structure with a cell size inversely proportional to the inter particle spacing (Chaubey et al. 2016).

Generally, the screw rotational speed is associated with the shear stress applied and the residence time of composite melt during compounding in an extruder. An increase in screw speed up will cause one of two distinct occurrences: (1) it will produce higher shear stress on the melt and thus promotes better distribution of the filler within the polymer matrix, which results in improved mechanical properties, or (2) it will reduce the residence time of melt in the extruder, which causes an incomplete melt compounding process (Ayyub et al. 2019). As for the effect of the screw speed on the tensile strength of PLA/BP composites, with varying screw speeds, no major difference was observed between the tensile strength values. This indicated that the impact of the screw speed on the mixing process of bamboo particles and PLA was of low significance, i.e., it did not impact the improvement of the tensile strength. Modifying the residence time of both the bamboo particles and the PLA or providing more shear did not help improve the mixing of both components, as the tensile strength remained similar for all the compounds tested. Gamon et al. (2013) also observed a small influence of screw speed on the mechanical properties of miscanthus/PLA composite.

The effect of the die temperature on the tensile strength appears to be drastic; a medium die temperature yielded the highest tensile strength in comparison to the tensile 
strength of samples produced using a low or high die temperature. Low die temperature composites did not impart any positive reinforcement by the fibres that were able to withstand stress transfer at the interface. Low die temperatures might lead to high viscosity, which results in poor mixing of the bamboo particles and PLA, thus exhibiting low tensile strength. The tensile strength also decreased with a high die temperature, which was associated with the softening of the matrix (Salleh et al. 2014).

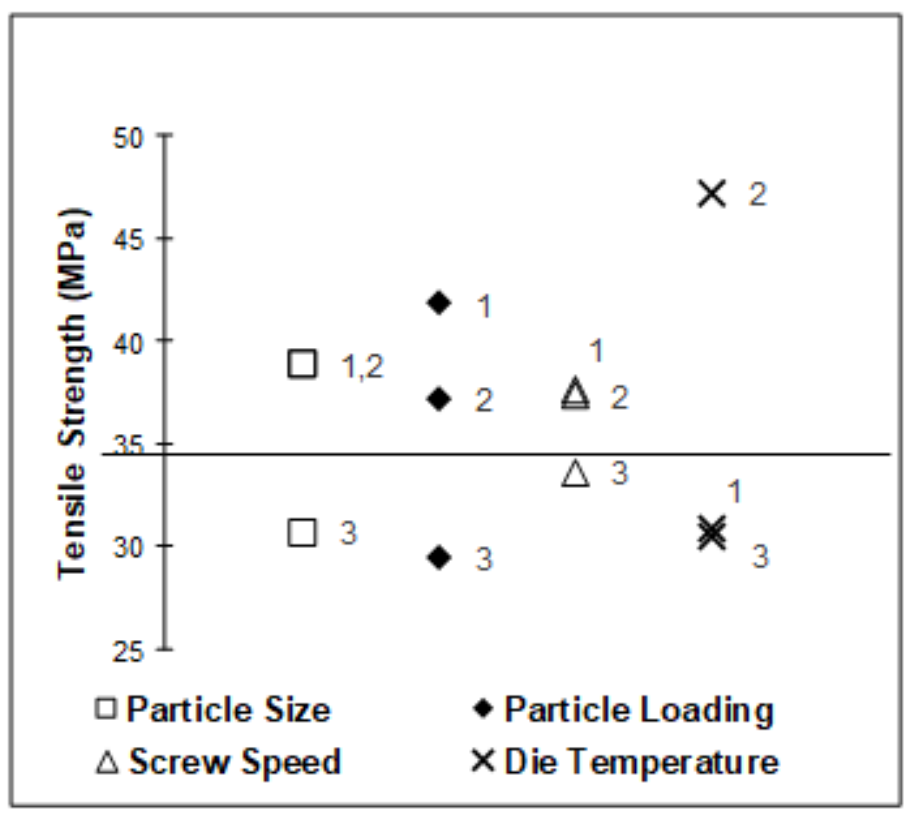

(a)

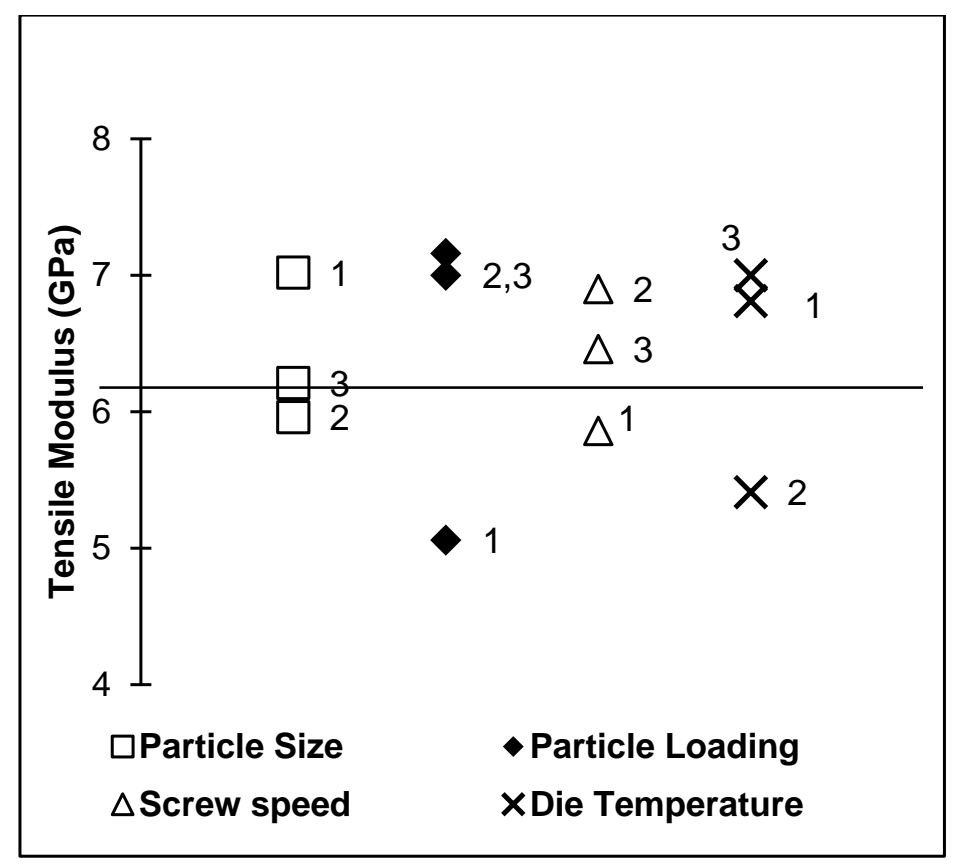

(b)

Fig. 4. Response graphs from the Taguchi analysis showing the average value of the tensile strength (a) and the tensile modulus (b) of the PLA/BP composites 


\section{Tensile modulus}

As shown in Fig. 4b, composites with a low particle size exhibit the highest tensile modulus. The results showed that low particle size can provide a greater stiffness effect. Stark and Berger (1997) also reported that the tensile modulus increased as the particle size increased, up to a particle size of approximately $250 \mu \mathrm{m}$, at which point the tensile values began to decrease. Meanwhile, composites with a medium and high particle size showed trivial differences, because at a given loading percentage, the fibre-matrix interaction in the composite system has been saturated (Mohamed et al. 2018). As expected, the tensile modulus is the lowest at a low loading percentage, since a higher bamboo load amount increases the stiffness of the composite, thus increasing the tensile modulus at higher bamboo particle loads (medium and high).

Based on the plot in Fig. 4b, a low screw speed yielded the lowest tensile modulus. A similar trend was found for jute fibre reinforced thermoplastic polypropylene (PP) composites processed using a twin-screw extruder with varying screw speeds $(100 \mathrm{rpm}$, $200 \mathrm{rpm}$, and $300 \mathrm{rpm}$ ) (Somashekhar et al. 2020). Their study revealed that the Young's modulus increases when the screw speed was changed from $100 \mathrm{rpm}$ to $300 \mathrm{rpm}$. At low screw speeds, the shear rate may not be sufficient in terms of wettability of the PLA matrix and lead to poor distribution of the filler within the polymer matrix, which results in a low tensile modulus. Based on the primary effect graphs, it can be concluded that particle load and die temperature appeared to significantly affect the tensile modulus of the composites synthesized with particle loads and die temperatures of $30 \mathrm{wt} \%$ and $190{ }^{\circ} \mathrm{C}$, respectively. By increasing the die temperature, the tensile modulus presented an increasing pattern compared to the ones processed at a lower temperature. Similar findings were reported in a study by Salleh et al. 2014).

\section{Flexural strength}

As shown in Fig. 5a, the maximum flexural strength was achieved by using a high particle size. However, there was only a slight difference in flexural strength values of the composites when the particle sizes differ. The same result was reported by Kuo et al. (2009). The particle load showed a notable influence on the flexural strength values of the composites. High particle loads led to the lowest flexural strength and an identical trend can be seen in tensile strength. Again, the reason for low flexural strength at high particle loads was due to the agglomeration of the fibres, which become a weak point in the composite. In addition, poor interaction between the bamboo particles and the PLA matrix could also be one of the reasons. These observations can be seen in the SEM images shown in Fig. 4. The Taguchi analysis suggests that the particle size, screw speed, and die temperature should be set to their highest level to obtain the highest flexural strength. However, changing the levels of these factors has little influence on the strength of the composite sheet. The particle loads should be set at a low level to achieve a high flexural strength with minimum product variability.

As for the screw speed, the flexural strength of the PLA/BP composites decreased as the screw speed was increased. Though the effect of the screw speed on the tensile strength was not impactful, it seemed to have an influence on the flexural strength. This might be due to the fact, as mentioned previously according to Leguillon et al. (2015), that amongst the two strength parameters, the tensile strength seems to be the only one that is a material parameter. Thus, any changes in process parameters might only affect the flexural strength and not on tensile strength. The die temperature appears to be randomly distributed 
and with various die temperatures; only slight changes were observed in the flexural modulus, so it can be assumed to be of trivial importance.

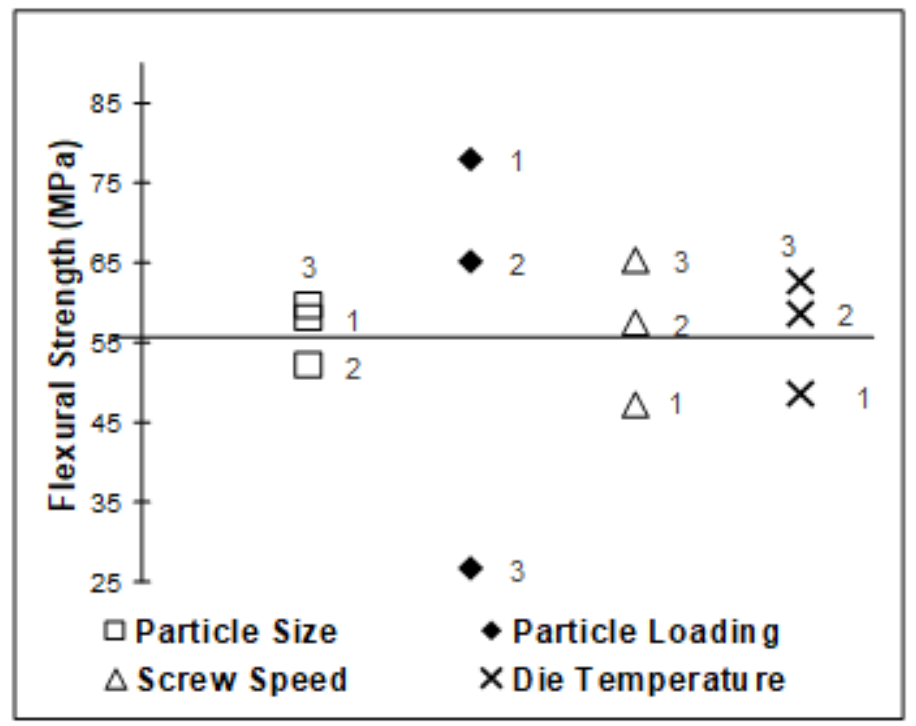

(a)

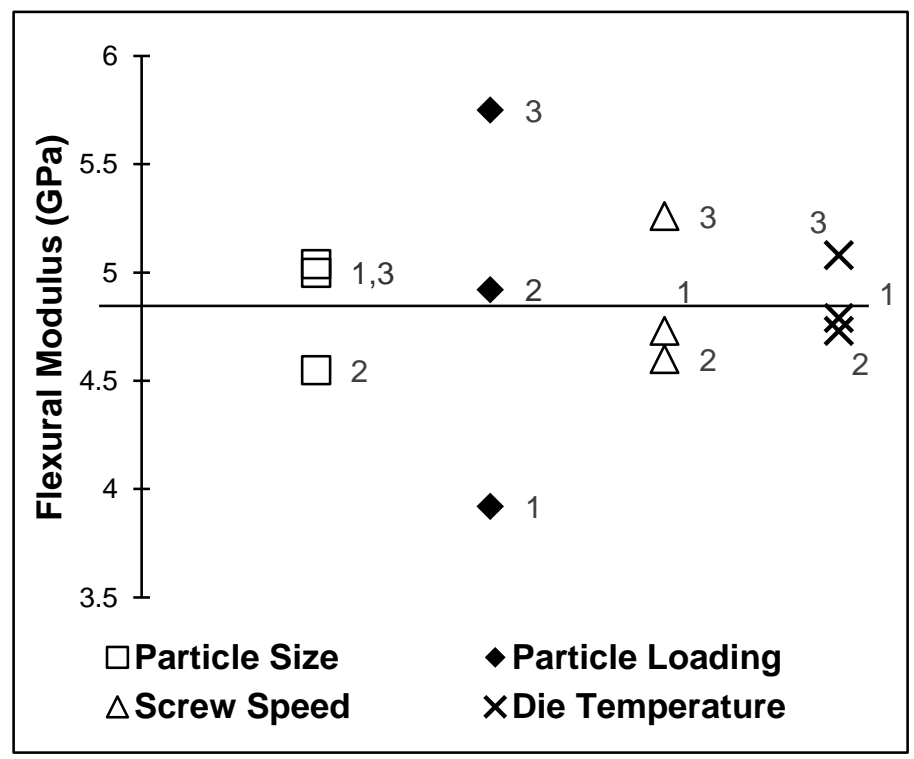

(b)

Fig. 5. Response graphs from the Taguchi analysis showing the average value of the flexural strength (a) and the flexural modulus (b) of the PLA/BP composites

\section{Flexural modulus}

The flexural modulus is a convenient measurement of the composite stiffness. Fillers can drastically contribute to an increase in stiffness. Therefore, the flexural modulus is highly dependent on particle size, and as such the flexural modulus increases as the particle size increases. As shown in Fig. 5b, the results of the flexural modulus analysis 
showed that a medium particle size yield the lowest value. This might be due to the weak wetting of medium size particles in comparison to the low and high particle sizes.

The greatest improvement in the flexural modulus with the inclusion of BP in the PLA composite was found at a particle load of $50 \mathrm{wt} \%$. A high particle load displayed the highest flexural modulus, which was due to the inclusion of bamboo particles that enhanced the flexural rigidity of the PLA composite. A high screw speed was found to contribute to a higher flexural modulus. This meant that a high screw speed created enough shear force to fully wet the bamboo particles, in comparison to low and medium particle sizes. Low and medium screw speeds yielded minimal difference in the flexural modulus. A similar trend was found for jute fibre reinforced thermoplastic polypropylene (PP) composite processed using a twin-screw extruder with varying screw speeds $(100 \mathrm{rpm}, 200 \mathrm{rpm}$, and $300 \mathrm{rpm}$ ) (Somashekhar et al. 2020). Their study revealed that the Young's modulus increased as the screw speed was increased from $100 \mathrm{rpm}$ to $300 \mathrm{rpm}$. At a low screw speed, the shear rate may not be sufficient for total wettability of the PLA matrix and can lead to poor distribution of the filler within the polymer matrix, which resulted in a low tensile modulus. Similar to tensile strength, the die temperature appears to be randomly distributed and with various die temperatures, only slight changes in the flexural modulus were observed on, so it can be assumed to be practically trivial.

\section{Impact strength}

Impact strength is an important parameter in measuring the plasticity of a material. The impact values reflect the ability of the material to absorb the energy transferred from a load (Sahin and Yayla 2005). Figure 6 shows that the composites with a low and high particle size resulted in the lowest impact strengths. The reason for the decrease in impact strength at low particle sizes may be due to the possibility of fibre agglomeration, which creates regions of stress concentration that require less energy for crack propagation to occur. Meanwhile, high particle size composites yielded a decrease in impact strength due to the stiffening of the polymer chain, which occurred due to fibre-matrix bonding (Nourbakhsh et al. 2009).

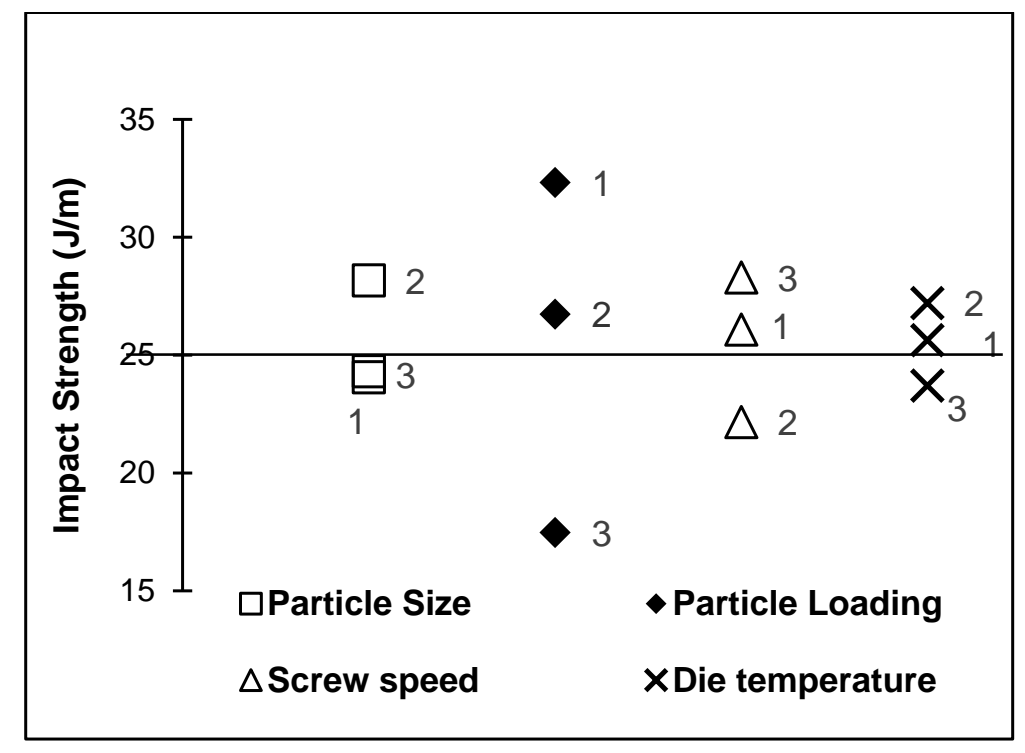

Fig. 6. Response graphs from the Taguchi analysis showing the average value of the impact strength of the PLA/bamboo composites 
The impact strength of the composites drastically decreased as the particle load increased. This was expected because the presence of bamboo particles in the PLA matrix provided stress concentration points, thus providing sites for crack initiation and potential composite failure. A high screw speed yielded the highest impact strength, while a medium screw speed had the lowest impact strength. A high screw speed resulted in a high shear rate in the twin screw extruder, which led to better distribution of the BP in the PLA matrix; therefore, more energy was absorbed when a point force was applied. However, a medium and low screw speed yielded lower impact strength because the shear rate was too low for the sufficient compounding of the BP and PLA, but the difference was minimal. The same result was also reported by Peltola et al. (2006), who stated that the screw speed did not have a noticeable influence on the rheological and mechanical properties of the PP nanoclay composites. The PLA/BP composites produced with a high die temperature yielded the lowest impact strength. However, the influence of the die temperature on the impact strength was negligible, since only small changes could be seen in the samples with different die temperatures. With regards to impact strength, as shown in Fig. 6, it appears that a medium particle size range $(150$ to $250 \mu \mathrm{m})$, a low particle load (10 wt \%), a high screw speed $(300 \mathrm{rpm})$, and a medium die temperature setting yielded the highest values for impact strength. This set of parameters are contrary to the optimum parameters obtained for the tensile and flexural properties.

\section{Analysis of Variance (ANOVA)}

To find the relative contribution of the parameters (particle size, particle loading, screw speed, and die temperature) on the tensile, flexural, and impact properties of the composites, ANOVA was performed on the experimental data. Table 4 shows the results of the ANOVA for the four output responses considered in this work. The results showed that the percentage contributions of the particle size, particle load, screw speed, and die temperature on the tensile strength were $2.81 \%, 34.74 \%, 9.48 \%$, and $52.97 \%$, respectively. In the case of the tensile modulus, the percentage contributions of the particle size, particle load, screw speed, and die temperature were 5.60\%, 57.05\%, 9.07\%, and $28.28 \%$, respectively. Regarding flexural strength, the percentage contributions of the particle size, particle load, screw speed, and die temperature were $1.44 \%, 78.85 \%, 11.86 \%$, and $7.85 \%$ respectively. The percentage contributions of particle size, particle load, screw speed, and die temperature on the flexural modulus were $2.97 \%, 79.16 \%, 14.84 \%$, and $3.03 \%$ respectively. For the impact strength, the percentage contributions of the particle size, particle load, screw speed, and die temperature on the flexural modulus were $6.86 \%$, $72.63 \%, 11.52 \%$, and $8.98 \%$, respectively.

The primary objective of the percentage contribution is to analyse which parameters significantly affect the tensile strength, tensile modulus, flexural strength, flexural modulus, and impact strength. The larger the value of the percentages, the greater the influence the parameter has on the response variable. It was observed that the die temperature and particle load contributed a higher percentage in comparison to the particle size and screw speed. It could also be seen that the $p$-value of the die temperature and particle load (approximately 0.0001 and 0.0017 , respectively) were less than alpha (0.05). Therefore, the authors rejected the null hypothesis. There was enough evidence to support the claim that at least one of the means is different. 
Table 4. Results of ANOVA

\begin{tabular}{|c|c|c|c|c|c|c|c|c|c|}
\hline \multirow{2}{*}{$\begin{array}{l}\text { Response/ } \\
\text { Factors }\end{array}$} & \multirow{2}{*}{$\begin{array}{c}\text { Sum of } \\
\text { Squared } \\
\text { Total (SST) }\end{array}$} & \multicolumn{4}{|c|}{ Sum of Squared (SS) } & \multicolumn{4}{|c|}{ Contribution (\%) } \\
\hline & & $\begin{array}{l}\text { Particle } \\
\text { Size }\end{array}$ & $\begin{array}{l}\text { Particle } \\
\text { Loading }\end{array}$ & $\begin{array}{l}\text { Screw } \\
\text { Speed }\end{array}$ & $\begin{array}{c}\text { Die } \\
\text { Temperature }\end{array}$ & $\begin{array}{l}\text { Particle } \\
\text { Size }\end{array}$ & $\begin{array}{l}\text { Particle } \\
\text { Loading }\end{array}$ & Screw Speed & $\begin{array}{c}\text { Die } \\
\text { Temperature }\end{array}$ \\
\hline $\begin{array}{l}\text { Tensile } \\
\text { strength }\end{array}$ & 3014.68 & 84.85 & 1047.38 & 285.65 & 1596.80 & $\begin{array}{c}2.81 \\
\left(0.6500^{\text {ns }}\right)\end{array}$ & $\begin{array}{c}34.74 \\
\left(0.0017^{\star}\right)\end{array}$ & $\begin{array}{c}9.48 \\
\left(0.2200^{\mathrm{ns}}\right)\end{array}$ & $\begin{array}{c}52.97 \\
\left(\sim 0.0001^{*}\right)\end{array}$ \\
\hline $\begin{array}{l}\text { Tensile } \\
\text { modulus }\end{array}$ & 66.83 & 3.74 & 38.13 & 6.06 & 18.90 & $\begin{array}{c}5.60 \\
\left(0.3813^{\text {ns }}\right)\end{array}$ & $\begin{array}{c}57.05 \\
\left(\sim 0.0001^{\star}\right)\end{array}$ & $\begin{array}{c}9.07 \\
\left(0.2042^{\text {ns }}\right)\end{array}$ & $\begin{array}{c}28.28 \\
\left(0.0040^{\star}\right)\end{array}$ \\
\hline $\begin{array}{l}\text { Flexural } \\
\text { strength }\end{array}$ & 18645.12 & 268.25 & 14701.58 & 2211.14 & 1464.15 & $\begin{array}{c}1.44 \\
\left(0.8220^{\mathrm{ns}}\right)\end{array}$ & $\begin{array}{c}78.85 \\
\left(\sim 0.0002^{*}\right)\end{array}$ & $\begin{array}{c}11.86 \\
\left(0.1807^{\mathrm{ns}}\right)\end{array}$ & $\begin{array}{c}7.85 \\
\left(0.3304^{\mathrm{ns}}\right)\end{array}$ \\
\hline $\begin{array}{l}\text { Flexural } \\
\text { modulus }\end{array}$ & 21.42 & 0.64 & 16.96 & 3.18 & 0.65 & $\begin{array}{c}2.97 \\
\left(0.6750^{\mathrm{ns}}\right)\end{array}$ & $\begin{array}{c}79.16 \\
\left(\sim 0.0001^{*}\right)\end{array}$ & $\begin{array}{c}14.84 \\
\left(0.1282^{\text {ns }}\right)\end{array}$ & $\begin{array}{c}3.03 \\
\left(0.6699^{n s}\right)\end{array}$ \\
\hline $\begin{array}{l}\text { Impact } \\
\text { strength }\end{array}$ & 1883.91 & 129.30 & 1368.30 & 217.05 & 169.26 & $\begin{array}{c}6.86 \\
\left(0.2471^{\mathrm{ns}}\right)\end{array}$ & $\begin{array}{c}72.63 \\
\left(\sim 0.0001^{\star}\right)\end{array}$ & $\begin{array}{c}11.52 \\
\left(0.0897^{\mathrm{ns}}\right)\end{array}$ & $\begin{array}{c}8.98 \\
\left(0.1569^{n s}\right)\end{array}$ \\
\hline
\end{tabular}

Nurul Fazita et al. (2021). "Bamboo- PLA composites," BioResources 16(1), 1914-1939. 1931 
Based on Table 4, it can also be seen that the greatest influence on the flexural strength, flexural modulus, and impact strength was the particle load. All $p$-values of the particle load for the flexural strength, flexural modulus, and impact strength (approximately 0.0002, approximately 0.0001, and approximately 0.0001) were less than alpha (0.05). Hence, the authors rejected the null hypothesis of equal population means and concluded that there was a statistically significant difference among the population means.

\section{Confirmation Test}

A set of optimum parameters that yields the most desirable mechanical properties for the PLA/BP composites is summarised in Table 5. To validate the set of parameters that had been suggested by the Taguchi analysis, which will improve the impact strength and provide acceptable tensile and flexural properties for the PLA/BP composites, a confirmation experiment was conducted. Confirmation experiments were carried out to determine the mechanical performance of the optimized parameter conditions. This test was essential to validate the conditions suggested by the Taguchi analysis, which yielded the "best" impact properties of the composites.

Table 5. Summary of Optimum Parameters Required to Achieve Maximum Mechanical Properties of PLA/BP Composites

\begin{tabular}{|c|c|c|c|c|c|}
\hline $\begin{array}{c}\text { Mechanical } \\
\text { Properties }\end{array}$ & $\begin{array}{c}\text { Tensile } \\
\text { Strength }\end{array}$ & $\begin{array}{c}\text { Tensile } \\
\text { modulus }\end{array}$ & $\begin{array}{c}\text { Flexural } \\
\text { Strength }\end{array}$ & $\begin{array}{c}\text { Flexural } \\
\text { Modulus }\end{array}$ & $\begin{array}{c}\text { Impact } \\
\text { Strength }\end{array}$ \\
\hline $\begin{array}{c}\text { Optimized } \\
\text { parameters }\end{array}$ & $\mathrm{A}_{2} \mathrm{~B}_{1} \mathrm{C}_{1} \mathrm{D}_{2}$ & $\mathrm{~A}_{1} \mathrm{~B}_{2} \mathrm{C}_{2} \mathrm{D}_{3}$ & $\mathrm{~A}_{3} \mathrm{~B}_{1} \mathrm{C}_{3} \mathrm{D}_{3}$ & $\mathrm{~A}_{3} \mathrm{~B}_{3} \mathrm{C}_{3} \mathrm{D}_{3}$ & $\mathbf{A}_{2} \mathrm{~B}_{1} \mathrm{C}_{3} \mathrm{D}_{2}{ }^{*}$ \\
\hline \multicolumn{3}{|l}{ Note: ${ }^{*}$ denotes the optimal parameters } \\
\hline
\end{tabular}

The set of parameters that yielded the optimum results for providing the highest impact strength in the PLA/BP composites was chosen for the confirmation test. A graph of primary effects plot shows that the parameter combination $\mathrm{A}_{2} \mathrm{~B}_{1} \mathrm{C}_{3} \mathrm{D}_{2}$ was the desired sequence for yielding maximum impact strength and acceptable tensile and flexural properties. Table 6 demonstrates the experimental results of the PLA/BP composites in the confirmation test. The increment of the tensile modulus, flexural modulus, and impact strength compared to pure PLA were $11.7 \%, 28 \%$, and 55\%, respectively.

Table 6. Experimental Results of Optimized Parameter PLA/BP Composite

\begin{tabular}{|c|c|c|c|c|c|c|c|c|}
\hline $\begin{array}{c}\text { Particle } \\
\text { Size }(\mu \mathrm{m})\end{array}$ & $\begin{array}{c}\text { Particle } \\
\text { Loading } \\
(\mathrm{wt} \%)\end{array}$ & $\begin{array}{c}\text { Screw } \\
\text { Speed } \\
(\mathrm{rpm})\end{array}$ & $\begin{array}{c}\text { Die } \\
\text { Temp. } \\
\left({ }^{\circ} \mathrm{C}\right)\end{array}$ & $\begin{array}{c}\text { Tensile } \\
\text { Strength } \\
(\mathrm{MPa})\end{array}$ & $\begin{array}{c}\text { Tensile } \\
\text { Modulus } \\
(\mathrm{GPa})\end{array}$ & $\begin{array}{c}\text { Flexural } \\
\text { Strength } \\
(\mathrm{MPa})\end{array}$ & $\begin{array}{c}\text { Flexural } \\
\text { Modulus } \\
(\mathrm{GPa})\end{array}$ & $\begin{array}{c}\text { Impact } \\
\text { Strength } \\
(\mathrm{J} / \mathrm{m})\end{array}$ \\
\hline $\begin{array}{c}150 \text { to } \\
250\end{array}$ & 10 & 300 & 180 & $\begin{array}{c}41.74 \\
(1.37)\end{array}$ & $\begin{array}{c}5.44 \\
(0.29)\end{array}$ & $\begin{array}{c}90.25 \\
(2.81)\end{array}$ & $\begin{array}{c}4.38 \\
(0.18)\end{array}$ & $\begin{array}{c}30.75 \\
(1.54)\end{array}$ \\
\hline
\end{tabular}




\section{CONCLUSIONS}

1. The tensile modulus, flexural modulus, and impact strength were improved with the presence of bamboo particles in comparison with neat poly(lactic acid) (PLA).

2. A graph of the main effects plot shows $A_{2} B_{1} C_{3} D_{2}$ as the desired sequence for maximum impact strength and acceptable tensile and flexural properties.

3. The results of the confirmation test showed a noticeable improvement in impact properties compared to neat PLA (a 55\% increase), without compromising tensile and flexural properties.

4. Through ANOVA analysis, the particle load was found to be the dominant factor influencing all the mechanical properties of the PLA/bamboo particles (BP) composites.

5. The ANOVA analysis also showed that the other parameters did not have a significant effect on the mechanical properties of the PLA/BP composites, however, die temperature had a significant influence on the tensile properties.

6. The findings from this study can help to give better insight on the factors that need to be considered carefully during the manufacturing of PLA/BP composites with better impact properties via extrusion moulding. The discoveries from this study also can be employed to predict the mechanical properties of PLA/BP composites under different extrusion moulding conditions. Specifically, the use of the DOE method with maximizing the desirability properties is a systematic approach to identify an optimal parameter setting of the extrusion moulding process. Hence, the efficiency of formulating an optimal solution is substantially improved and the trialand-error process can be prevented.

\section{ACKNOWLEDGEMENTS}

The authors gratefully acknowledge the financial support from the Universiti Sains Malaysia (USM) under the Research University Grant (RUI) (1001.PTEKIND.8011098) and the Ministry of Higher Education, Malaysia for Fundamental Research Grant Scheme (FRGS) (203/PTEKIND.6711819).

\section{REFERENCES CITED}

ASTM D256-10 (2018). "Standard test methods for determining the Izod pendulum impact resistance of plastics," ASTM International. West Conshohocken, PA.

ASTM D638-10 (2010). "Standard test method for tensile properties of plastics," ASTM International. West Conshohocken, PA.

ASTM D790-10 (2010). "Standard test methods for flexural properties of unreinforced and reinforced plastics and electrical insulating materials," ASTM International, West Conshohocken, PA.

Ayyub, K. T., Moravkar, K., Maniruzzaman, M., and Amin, P. (2019). "Effect of melt extrudability and melt binding efficiency of polyvinyl caprolactam polyvinyl acetate polyethylene glycol graft copolymer (Soluplus®) on release pattern of hydrophilic 
and high dose drugs," Materials Science and Engineering: C 99, 563-574. DOI: 10.1016/j.msec.2019.01.126

Bax, B., and Müssig, J. (2008). "Impact and tensile properties of PLA/Cordenka and PLA/flax composites,” Composites Science and Technology 68(7-8), 1601-1607. DOI: 10.1016/j.compscitech.2008.01.004

Bhairav, B. A., Kokane, P. A., and Saudagar, R. B. (2016). "Hot melt extrusion technique-A review," Research Journal of Science and Technology 8(3), 155-162. DOI: $10.5958 / 2349-2988.2016 .00022 . x$

Bledzki, A. K., and Jaszkiewicz, A. (2010). "Mechanical performance of biocomposites based on PLA and PHBV reinforced with natural fibres - A comparative study to PP," Composites Science and Technology 70(12), 1687-1696. DOI: 10.1016/j.compscitech.2010.06.005

Boontima, B., Noomhorm, A., Puttanlek, C., Uttapap, D., and Rungsardthong, V. (2015). "Mechanical properties of sugarcane bagasse fiber-reinforced soy based biocomposites," Journal of Polymers and the Environment 23(1), 97-106. DOI: 10.1007/s10924-014-0679-2

Bourmaud, A., and Baley, C. (2010). "Effects of thermo mechanical processing on the mechanical properties of biocomposite flax fibers evaluated by nanoindentation," Polymer Degradation and Stability 95(9), 1488-1494. DOI: 10.1016/j.polymdegradstab.2010.06.022

Bourmaud, A., Corre, Y.-M., and Baley, C. (2015). "Fully biodegradable composites: Use of poly-(butylene-succinate) as a matrix and to plasticize L-poly-(lactide)-flax blends," Industrial Crops and Products 64, 251-257. DOI: 10.1016/j.indcrop.2014.09.033

Chan, C., Vandi, L.-J., Pratt, S., Halley, P., Richardson, D., Werker, A., and Laycock, B. (2016). "Processing and characterization of polyhydroxyalkanoate (PHA)-based wood plastic composites: Effect of non-reactive additives," in: Proceedings of the Fibre Value Chain Conference and Expo 2016: Pulp and Paper Bioenergy Bioproducts, 12-14 October, Rotorua, New Zealand, pp. 57-66.

Chaubey, A. K., Konda Gokuldoss, P., Wang, Z., Scudino, S., Mukhopadhyay, N. K., and Eckert, J. (2016). "Effect of particle size on microstructure and mechanical properties of Al-based composite reinforced with 10 vol.\% mechanically alloyed Mg-7.4\% $\mathrm{Al}$ particles," Technologies 4(4), 37. DOI:10.3390/technologies4040037

Chen, T., Wu, Y., Qiu, J., Fei, M., Qiu, R., and Liu, W. (2020). “Interfacial compatibilization via in-situ polymerization of epoxidized soybean oil for bamboo fibers reinforced poly ( lactic acid ) biocomposites," Composites Part A: Applied Science and Manufacturing 138, 106066. DOI: 10.1016/j.compositesa.2020.106066.

Chougan, M., Ghaffar, S. H., Al-Kheetan, M. J., and Gecevicius, M. (2020). "Wheat straw pre-treatments using eco-friendly strategies for enhancing the tensile properties of bio-based polylactic acid composites," Industrial Crops and Products 155, 112836. DOI: 10.1016/j.compositesa.2017.04.005

Duhovic, M., Horbach, S., and Bhattacharyya, D. (2009). "Improving the interface strength in flax fibre poly(lactic) acid composites," Journal of Biobased Materials and Bioenergy 3(2), 188-198. DOI: 10.1166/jbmb.2009.1017

El-Shekeil, Y. A., Sapuan, S. M., Jawaid, M., and Al-Shuja'A, O. M. (2014). 'Influence of fiber content on mechanical, morphological and thermal properties of kenaf fibers reinforced poly(vinyl chloride)/thermoplastic polyurethane poly-blend composites," Materials \& Design 58, 130-135. DOI: 10.1016/j.matdes.2014.01.047 
Fu, S.-Y., Feng, X.-Q., Lauke, B., and Mai, Y.-W. (2008). "Effects of particle size, particle/matrix interface adhesion and particle loading on mechanical properties of particulate-polymer composites," Composites Part B: Engineering 39(6), 933-961. DOI: 10.1016/j.compositesb.2008.01.002

Gallos, A., Paës, G., Allais, F., and Beaugrand, J. (2017). 'Lignocellulosic fibers: A critical review of the extrusion process for enhancement of the properties of natural fiber composites," RSC Advances 7(55), 34638-34654. DOI: 10.1039/c7ra05240e

Gamon, G., Evon, P., and Rigal, L. (2013). "Twin-screw extrusion impact on natural fibre morphology and material properties in poly (lactic acid) based biocomposites," Industrial Crops and Products 46, 173-185. DOI:10.1016/j.indcrop.2013.01.026

Ghaffar, S. H., Fan, M., and McVicar, B. (2017). "Interfacial properties with bonding and failure mechanisms of wheat straw node and internode," Composites Part A: Applied Science and Manufacturing 99, 102-112. DOI: 10.1016/j.indcrop.2020.112836

Ghaffar, S. H., Madyan, O. A., Fan, M., and Corker, J. (2018). "The influence of additives on the interfacial bonding mechanisms between natural fibre and biopolymer composites," Macromolecular Research 26, 851-863. DOI:10.1007/s13233-018-6119-8

Gupta, A., Singh, H., and Walia, R. S. (2016). "Hybrid filler composition optimization for tensile strength of jute fibre-reinforced polymer composite," Bulletin of Materials Science 39(5), 1223-1231. DOI: 10.1007/s12034-016-1248-1

Ho, M., Lau, K., Wang, H., and Hui, D. (2015). "Improvement on the properties of polylactic acid (PLA) using bamboo charcoal particles," Composites Part B: Engineering 81, 14-25. DOI: 10.1016/j.compositesb.2015.05.048

Ismail, H., Edyham, M. R., and Wirjosentono, B. (2002). "Bamboo fiber filled natural rubber composites: The effects of filler loading and bonding agent," Polymer Testing 21(2), 139-144. DOI: 10.1016/s0142-9418(01)00060-5

Iwatake, A., Nogi, M., and Yano, H. (2008). "Cellulose nanofiber-reinforced polylactic acid,” Composites Science and Technology 68(9), 2103-2106. DOI: 10.1016/j.compscitech.2008.03.006

Joseph, E. J., and Panneerselvam, K. (2020). "Effect of particulate fillers on mechanical, metallurgical and abrasive behavior of tungsten reinforced HDPE composites: A Taguchi approach," Materials Today: Proceedings (in-press). DOI: 10.1016/j.matpr.2020.04.042

Jumaidin, R., Sapuan, S. M., Jawaid, M., Ishak, M. R., and Sahari, J. (2017). “Thermal, mechanical, and physical properties of seaweed/sugar palm fibre reinforced thermoplastic sugar palm starch/agar hybrid composites," International Journal of Biological Macromolecules 97, 606-615. DOI: 10.1016/j.ijbiomac.2017.01.079

Klyosov, A. A. (2007). Wood-Plastic Composites, John Wiley \& Sons, Inc, Hoboken, NJ. DOI: $10.1002 / 9780470165935$

Kuo, P.-Y., Wang, S.-Y., Chen, J.-H., Hsueh, H.-C., and Tsai, M.-J. (2009). "Effects of material compositions on the mechanical properties of wood-plastic composites manufactured by injection molding," Materials \& Design 30(9), 3489-3496. DOI: 10.1016/j.matdes.2009.03.012

Lee, S.-H., and Wang, S. (2006). "Biodegradable polymers/bamboo fiber biocomposite with bio-based coupling agent," Composites Part A: Applied Science and Manufacturing 37(1), 80-91. DOI: 10.1016/j.compositesa.2005.04.015 
Leguillon, D., Martin, É., and Lafarie-Frenot, M.-C. (2015). "Flexural vs. tensile strength in brittle materials," Comptes Rendus Mécanique 343(4), 275-281. DOI:

10.1016/j.crme.2015.02.003

Liu, W., Hui, C., Wang, F., Wang, M., and Liu, G. (2018). "Review of the resources and utilization of bamboo in China," in: Bamboo - Current and Future Prospects, H. P. S. Abdul Khalil (ed.), IntechOpen Limited, London, United Kingdom, pp. 1-10. DOI: 10.5772/intechopen.76485

Long, H., Wu, Z., Dong, Q., Shen, Y., Zhou, W., Luo, Y., Zhang, C., and Dong, X. (2019). "Effect of polyethylene glycol on mechanical properties of bamboo fiberreinforced polylactic acid composites," Journal of Applied Polymer Science 136(26), 3-10. DOI: 10.1002/app.47709.

Lu, T., Liu, S., Jiang, M., Xu, X., Wang, Y., Wang, Z., Zhou, Z., Gou, J., Hui, D., and Zhou, Z. (2014). "Effects of modifications of bamboo cellulose fibers on the improved mechanical properties of cellulose reinforced poly(lactic acid) composites," Composites Part B: Engineering 62, 191-197. DOI:

10.1016/j.compositesb.2014.02.030

Masirek, R., Kulinski, Z., Chionna, D., Piorkowska, E., and Pracella, M. (2007). "Composites of poly(L-lactide) with hemp fibers: Morphology and thermal and mechanical properties," Journal of Applied Polymer Science 105(1), 255-268. DOI: 10.1002/app.26090

Mohamed, W. Z. W., Baharum, A., Ahmad, I., Abdullah, I., and Zakaria, N. E. (2018) "Effects of fiber size and fiber content on mechanical and physical properties of mengkuang reinforced thermoplastic natural rubber composites," BioResources 13(2), 2945-2959. DOI: 10.15376/biores.13.2.2945-2959

Mulinari, D. R., Voorwald, H. J. C., Cioffi, M. O. H., da Silva, M. L. C. P., da Cruz, T. G., and Saron, C. (2009). "Sugarcane bagasse cellulose/HDPE composites obtained by extrusion," Composites Science and Technology 69(2), 214-219. DOI:

10.1016/j.compscitech.2008.10.006

Navaneethakrishnan, S., and Athijayamani, A. (2015). "Taguchi method for optimization of fabrication parameters with mechanical properties in fiber and particulate reinforced composites," International Journal of Plastics Technology 19(2), 227-240. DOI: $10.1007 / \mathrm{s} 12588-015-9128-\mathrm{x}$

Nourbakhsh, A., Karegarfard, A., Ashori, A., and Nourbakhsh, A. (2009). "Effects of particle size and coupling agent concentration on mechanical properties of particulate-filled polymer composites," Journal of Thermoplastic Composite Materials 23(2), 169-174. DOI: 10.1177/0892705709340962

Nuthong, W., Uawongsuwan, P., Pivsa-Art, W., and Hamada, H. (2013). "Impact property of flexible epoxy treated natural fiber reinforced PLA composites," Energy Procedia 34, 839-847. DOI: 10.1016/j.egypro.2013.06.820

Ochi, S. (2008). "Mechanical properties of kenaf fibers and kenaf/PLA composites," Mechanics of Materials 40(4-5), 446-452. DOI: 10.1016/j.mechmat.2007.10.006

Ogbomo, S. M., Chapman, K., Webber, C., Bledsoe, R., and D'souza, N. A. (2009). "Benefits of low kenaf loading in biobased composites of poly(L-lactide) and kenaf fiber," Journal of Applied Polymer Science 112(3), 1294-1301. DOI: 10.1002/app.29519

Pan, P., Zhu, B., Kai, W., Serizawa, S., Iji, M., and Inoue, Y. (2007). 'Crystallization behavior and mechanical properties of bio-based green composites based on poly(L- 
lactide) and kenaf fiber," Journal of Applied Polymer Science 105(3), 1511-1520. DOI: 10.1002/app.26407

Peltola, P., Välipakka, E., Vuorinen, J., Syrjälä, S., and Hanhi, K. (2006). "Effect of rotational speed of twin screw extruder on the microstructure and rheological and mechanical properties of nanoclay-reinforced polypropylene nanocomposites," Polymer Engineering \& Science 46(8), 995-1000. DOI: 10.1002/pen.20586

Ragoubi, M., George, B., Molina, S., Bienaimé, D., Merlin, A., Hiver, J.-M., and Dahoun, A. (2012). "Effect of corona discharge treatment on mechanical and thermal properties of composites based on miscanthus fibres and polylactic acid or polypropylene matrix," Composites Part A: Applied Science and Manufacturing 43(4), 675-685. DOI: 10.1016/j.compositesa.2011.12.025

Rassiah, K., Megat Ahmad, M. M. H., Ali, A., Abdullah, A. H., and Nagapan, S. (2017). "Mechanical properties of layered laminated woven bamboo Gigantochloa Scortechinii/epoxy composites," Journal of Polymers and the Environment 26(4), 1328-1342. DOI: 10.1007/s10924-017-1040-3

Rawi, N. F., Jayaraman, K., and Bhattacharyya, D. (2013). "A performance study on composites made from bamboo fabric and poly(lactic acid)," Journal of Reinforced Plastics and Composites 32(20), 1513-1525. DOI: 10.1177/0731684413498296

Rosato, D. V. (2013). Extruding Plastics: A Practical Processing Handbook, Springer Science \& Business Media, Berlin, Germany.

Sahin, S., and Yayla, P. (2005). "Effects of processing parameters on the mechanical properties of polypropylene random copolymer," Polymer Testing 24(8), 1012-1021. DOI: 10.1016/j.polymertesting.2005.07.010

Salleh, F., Hassan, A., Yahya, R., and Azzahari, A. D. (2014). "Effects of extrusion temperature on the rheological, dynamic mechanical and tensile properties of kenaf fiber/HDPE composites," Composites Part B: Engineering 58, 259-266. DOI: 10.1016/j.compositesb.2013.10.068

Sallih, N., Lescher, P., and Bhattacharyya, D. (2014). "Factorial study of material and process parameters on the mechanical properties of extruded kenaf fibre/polypropylene composite sheets," Composites Part A: Applied Science and Manufacturing 61, 91-107. DOI: 10.1016/j.compositesa.2014.02.014

Sarasini, F., Tirillò, J., Puglia, D., Dominici, F., Santulli, C., Boimau, K., Valente, T., and Torre, L. (2017). "Biodegradable polycaprolactone-based composites reinforced with ramie and borassus fibres," Composite Structures 167, 20-29. DOI:

10.1016/j.compstruct.2017.01.071

Sawpan, M. A., Pickering, K. L., and Fernyhough, A. (2011). "Improvement of mechanical performance of industrial hemp fibre reinforced polylactide biocomposites," Composites Part A: Applied Science and Manufacturing 42(3), 310319. DOI: 10.1016/j.compositesa.2010.12.004

Shah, A. U., Sultan, M. T. H., Jawaid, M., Cardona, F., and Talib, A. R. (2016). "A review on the tensile properties of bamboo fiber reinforced polymer composites," BioResources 11(4). DOI: 10.15376/biores.11.4.shah

Shibata, M., Oyamada, S., Kobayashi, S., and Yaginuma, D. (2004). "Mechanical properties and biodegradability of green composites based on biodegradable polyesters and lyocell fabric," Journal of Applied Polymer Science 92(6), 3857-3863. DOI: 10.1002/app.20405

Siakeng, R., Jawaid, M., Ariffin, H., and Sapuan, S. M. (2017). "Physical properties of coir and pineapple leaf fibre reinforced polylactic acid hybrid composites," in: 
Proceedings of the International Conference on Advances in Manufacturing and Materials Engineering (ICAMME 2017), 8-9 August, Kuala Lumpur, Malaysia, pp. 16. DOI: $10.1088 / 1757-899 x / 290 / 1 / 012031$

Somashekhar, S., Shanthakumar, G. C., and Nagamadhu, M. (2020). "Influence of fiber content and screw speed on the mechanical characterization of jute fiber reinforced polypropylene composite using Taguchi method," Materials Today: Proceedings 24(4), 2366-2374. DOI: 10.1016/j.matpr.2020.03.766

Stark, N. M., and Berger, M. J. (1997) "Effect of species and particle size on properties of wood-flour-filled polypropylene composites," in: Proceeding of the Functional Fillers for Thermoplastic and Thermosets, 8-10 December, San Diego, California, pp. $1-10$.

Tokoro, R., Vu, D. M., Okubo, K., Tanaka, T., Fujii, T., and Fujiura, T. (2008). "How to improve mechanical properties of polylactic acid with bamboo fibers," Journal of Materials Science 43(2), 775-787. DOI: 10.1007/s10853-007-1994-y

Torres-Tello, E. V., Robledo-Ortíz, J. R., González-García, Y., Pérez-Fonseca, A. A., Jasso-Gastinel, C. F., and Mendizábal, E. (2017). "Effect of agave fiber content in the thermal and mechanical properties of green composites based on polyhydroxybutyrate or poly(hydroxybutyrate-co-hydroxyvalerate)," Industrial Crops and Products 99, 117-125. DOI: 10.1016/j.indcrop.2017.01.035

Treece, M. A., and Oberhauser, J. P. (2006). "Processing of polypropylene-clay nanocomposites: Single-screw extrusion with in-line supercritical carbon dioxide feed versus twin-screw extrusion," Journal of Applied Polymer Science 103(2), 884-892. DOI: 10.1002/app.25226

Wahyuni, N. L. E., and Soeswanto, B. (2019). "The effects of particle size and content on morphology and mechanical properties of rice straw and coal fly ash filledpolypropylene composites," in: Journal of Physics: Conference Series (Vol. 1175, No. 1, p. 012282). IOP Publishing. DOI:10.1088/1742-6596/1175/1/012282

Wang, F., Yang, M., Zhou, S., Ran, S., and Zhang, J. (2017). "Effect of fiber volume fraction on the thermal and mechanical behavior of polylactide-based composites incorporating bamboo fibers," Journal of Applied Polymer Science 135(15), 46148. DOI: 10.1002/app.46148

Yang, H.-S., Kim, H.-J., Son, J., Park, H.-J., Lee, B.-J., and Hwang, T.-S. (2004). "Ricehusk flour filled polypropylene composites; Mechanical and morphological study," Composite Structures 63(3-4), 305-312. DOI: 10.1016/s0263-8223(03)00179-X

Yang, T.-C., Wu, T.-L., Hung, K.-C., Chen, Y.-L., and Wu, J.-H. (2015). "Mechanical properties and extended creep behavior of bamboo fiber reinforced recycled poly(lactic acid) composites using the time-temperature superposition principle," Construction and Building Materials 93, 558-563. DOI:

10.1016/j.conbuildmat.2015.06.038

Yu, Y., Huang, X., and Yu, W. (2014). "A novel process to improve yield and mechanical performance of bamboo fiber reinforced composite via mechanical treatments," Composites Part B: Engineering 56, 48-53. DOI: 10.1016/j.compositesb.2013.08.007

Yu, Y., Wang, H., Lu, F., Tian, G., and Lin, J. (2013). "Bamboo fibers for composite applications: A mechanical and morphological investigation," Journal of Materials Science 49(6), 2559-2566. DOI: 10.1007/s10853-013-7951-z 
Yu, Y., Zhu, R., Wu, B., Hu, Y., and Yu, W. (2014). "Fabrication, material properties, and application of bamboo scrimber," Wood Science and Technology 49(1), 83-98. DOI: $10.1007 / \mathrm{s} 00226-014-0683-7$

Zakaria, N. E., Ahmad, I., Wan Mohamad, W. Z., and Baharum, A. (2018). "Effects of fibre size on Sansevieria trifasciata/natural rubber/high density polyethylene biocomposites," Malaysian Journal of Analytical Sciences, 22(6), 1057-1064. DOI: 10.17576/mjas-2018-2206-16

Zhang, C., Wang, W., Huang, Y., Pan, Y., Jiang, L., Dan, Y., Luo, Y., and Peng, Z. (2013). "Thermal, mechanical and rheological properties of polylactide toughened by expoxidized natural rubber," Materials \& Design 45, 198-205. DOI: 10.1016/j.matdes.2012.09.024

Zhang, S., Cao, X. Y., Ma, Y. M., Ke, Y. C., Zhang, J. K., and Wang, F. S. (2011). "The effects of particle size and content on the thermal conductivity and mechanical properties of $\mathrm{Al}_{2} \mathrm{O}_{3}$ /high density polyethylene (HDPE) composites," Express Polymer Letters 5(7), 581-590. DOI: 10.3144/expresspolymlett.2011.57

Zhang, S., Liang, Y., Qian, X., Hui, D., and Sheng, K. (2020). "Pyrolysis kinetics and mechanical properties of poly (lactic acid)/bamboo particle biocomposites: Effect of particle size distribution," Nanotechnology Reviews, 9(1), 524-533. DOI: 10.1515/ntrev-2020-0037

Zhao, Q., Tao, J., Yam, R. C. M., Mok, A. C. K., Li, R. K. Y., and Song, C. (2008). "Biodegradation behavior of polycaprolactone/rice husk ecocomposites in simulated soil medium," Polymer Degradation and Stability 93(8), 1571-1576. DOI: 10.1016/j.polymdegradstab.2008.05.002

Zhou, Y., Fan, M., and Chen, L. (2016). "Interface and bonding mechanisms of plant fiber composites: An overview," Composites Part B: Engineering 101, 31-45. DOI: 10.1016/j.compositesb.2016.06.055

Zuo, Y., Chen, K., Li, P., He, X., Li, W., and Wu, Y. (2020). "Effect of nano-SiO 2 on the compatibility interface and properties of polylactic acid-grafted-bamboo fiber/polylactic acid composite," International Journal of Biological Macromolecules 157, 177-186. DOI: 10.1016/j.ijbiomac.2020.04.205.

Article submitted: September 27, 2020; Peer review completed: October 31, 2020; Revised version received and accepted: January 21, 2021; Published: January 26, 2021.

DOI: 10.15376/biores.16.1.1914-1939 